Southeast Europe Journal of Soft Computing Volume 1. Number 1 March 2012

\title{
Cournot Model of Duopoly with Incomplete Information
}

\author{
Mehmet Can \\ International University of Sarajevo, \\ Paromlinska, 66, Sarajevo, Bosnia and Herzegovina \\ mcan@ius.edu.ba
}

\begin{abstract}
:
Cournot (1838) anticipated Nash's definition of equilibrium by over a century, but only in the context of a particular model of duopoly. Not surprisingly, Cournot's work is one of the classics of game theory; it is also one of the cornerstones of the theory of industrial organization. We consider a modification of the Cournot's model with an uncertainty in the demand. We find the Bayesian Nash equilibrium of the game.
\end{abstract}

\section{INTRODUCTION}

Negotiating about the shares is costly, and the pie may decay or disappear if the negotiations go on for very long. At least since Edgeworth (1881) bargaining has been perceived as an important question in economics and political science. Nash (1950, 1953) used both the cooperative or axiomatic approach and the noncooperative one in his work on bargaining; he first characterized the unique outcome satisfying a set of axioms, and then proposed a non-cooperative game whose equilibrium was precisely this outcome. However, Nash's noncooperative model assumed that players had only one chance to reach an agreement, and that if they failed to do so they were unable to continue negotiating. This game seemed too simple to capture the richness of bargaining, and the noncooperative approach to bargaining received little attention until the 1970 s.

\section{COURNOT DUAPOLY MODEL WITH COMPLETE INFORMATION}

Let $q_{1}$ and $q_{2}$ denote the quantities of a homogeneous product produced by firms 1 and 2, respectively. Let $\mathrm{P}(\mathrm{Q})=$ a - $\mathrm{Q}$ be the market-clearing price when the aggregate quantity on the market is $\mathrm{Q}=q_{1}+q_{2}$.

Assume that the total cost to firm i of producing quantity $q_{i}$ is $C_{i}\left(q_{i}\right)=c q_{i}, 0 \leq c \leq 1$. That is, there are no fixed costs, and the marginal cost is constant at c. Following Cournot, suppose that the firms 
choose their quantities simultaneously.

In order to find the Nash equilibrium of the Cournot game, we first translate the problem into a normal-form game. Recall from the previous section that the normal-form representation of a game specifies:

(1) the players in the game,

(2) the strategies available to each player, and

(3) the payoff received by each player for each combination of strategies that could be chosen by the players.

There are of course two players in any duopoly game, the two firms. In the Cournot model, the strategies available to each firm are the different quantities it might produce. We will assume that output is continuously divisible. Naturally, negative outputs are not feasible. Thus, each firm's strategy space can be represented as $S_{i}=[0, \infty)$, the nonnegative real numbers, in which case a typical strategy $s_{i}$ is a quantity choice, $q_{i}>0$. One could argue that extremely large quantities are not feasible and so should not be included in a firm's strategy space. Because $P(Q)=0$ for $\mathrm{Q}>\mathrm{a}$, however, neither firm will produce a quantity $q_{i}>a$.

It remains to specify the payoff to firm $i$ as a function of the strategies chosen by it and by the other firm, and to define and solve for equilibrium. We assume that the firm's payoff is simply its profit. Thus, the payoff $u_{i}\left(s_{i}, s_{j}\right)$ in a general two-player game in normal form can be written here as

$$
\begin{aligned}
& u_{i}\left(q_{i}, q_{j}\right)=q_{i}\left(P\left(q_{i}+q_{j}\right)-c\right) \\
& =q_{i}\left(a-\left(q_{i}+q_{j}\right)-c\right)
\end{aligned}
$$

he strategy pair $\left(s_{1}^{*}, s_{2}^{*}\right)$ is a Nash equilibrium if, for each player $i$

$u_{i}\left(s_{i}^{*}, s_{j}^{*}\right) \geq u_{i}\left(s_{i}, s_{j}^{*}\right), \quad \forall s_{i} \in S_{i}$.

Equivalently, for each player $i, s_{i}^{*}$ must solve the optimization problem $\operatorname{Max}_{s_{i} \in S_{i}} u_{i}\left(s_{i}, s_{j}^{*}\right)$.

In the Cournot duopoly model, the analogous statement is that the quantity pair $\left(q_{1}^{*}, q_{2}^{*}\right)$ is a Nash equilibrium if, for each firm $i, q_{i}^{*}$ solves

$\operatorname{Max}_{0 \leq q_{\mathrm{i}}<\infty} u_{i}\left(q_{i}, q_{j}^{*}\right)=\operatorname{Max}_{0 \leq q_{\mathrm{i}}<\infty} q_{i}\left(a-\left(q_{i}+q_{j}^{*}\right)-c\right)$ Assuming $q_{j}^{*}<a-c \quad$ (as will be shown to be true), the first-order condition for firm i's optimization problem, which is obtained by equating the derivative of the payoff function

$$
\begin{aligned}
& \frac{d u_{i}\left(q_{i}, q_{j}^{*}\right)}{d q_{i}}=a-\left(q_{i}+q_{j}^{*}\right)-c+q_{i}(-1) \\
& =a-\left(2 q_{i}+q_{j}^{*}\right)-c
\end{aligned}
$$

To zero is both necessary and sufficient; it yields

$q_{i}=\frac{1}{2}\left(a-q_{j}^{*}-c\right)$.

Thus, if the quantity pair $\left(q_{1}^{*}, q_{2}^{*}\right)$ is to be a Nash equilibrium, the firms' quantity choices must satisfy

$q_{1}^{*}=\frac{1}{2}\left(a-q_{2}^{*}-c\right), \quad q_{2}^{*}=\frac{1}{2}\left(a-q_{1}^{*}-c\right)$.

Simultaneous solutions of these two linear algebraic equations in $\left(q_{i}, q_{j}\right)$ leads to

$q_{1}^{*}=q_{2}^{*}=\frac{1}{3}(a-c)$ 
Southeast Europe Journal of Soft Computing Volume 1. Number 1 March 2012

Which are indeed less than $a-c$, as assumed.

If we approach to the problem graphically, the two best-response functions

$u_{i}\left(q_{i}, q_{j}\right)=q_{i}\left(a-\left(q_{i}+q_{j}\right)-c\right), i=1,2$

intersect only once, at the equilibrium quantity pair $q_{1}^{*}=q_{2}^{*}=(1-c) / 3$.

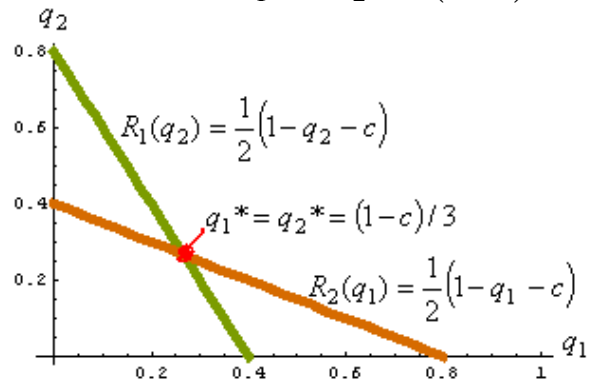

Figure 1. Equilibrium quantity pair $q_{1}{ }^{*}=q_{2}{ }^{*}=(1-c) / 3$ for $\mathrm{c}=0.2$.

The value $u_{i}\left(\frac{1-c}{3}, \frac{1-c}{3}\right)=\left(\frac{1-c}{3}\right)^{2}$ of the utility function $u_{i}\left(q_{i}, q_{j}\right)$ at $q_{i}=(1-c) / 3$ dominates its values at any other value of $q_{i}$, when player $j$ plays $q_{j}=(a-c) / 3$. The same is true for the player $j$. Therefore $q_{i}{ }^{*}=q_{j}{ }^{*}=(1-c) / 3 \quad$ is a Nash equilibrium.

A three dimensional picture of the Nash equilibrium can be given as follows:

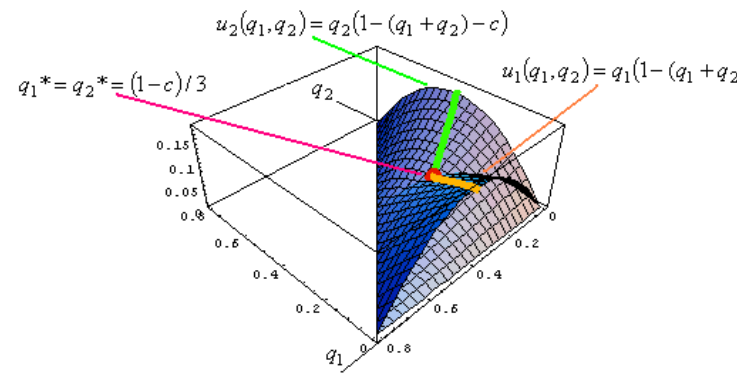

Figure 2. Playoff surfaces for two buyers and the equilibrium point.

\section{COURNOT DUAPOLY MODEL WITH INCOMPLETE INFORMATION}

Let us modify Cournout duopoly model with complete information into one with incomplete information simply changing certain matket demand a with an uncertain high demand $a_{H}$ with probability $\theta$, and a low demand $a_{L}$ with probability $1-\theta$ (Gibbons, 1992). Furthermore information is asymmetric: firm 1 knows whether demand is high or low, but firm 2 does not. All of this is common knowledge. The two firms simultaneously choose quantities.

Then the expected utilities of firm 1 will be

$$
\begin{aligned}
& u_{1}\left(q_{1}, q_{2 H}, q_{2 L}\right)=\theta q_{1}\left(a_{H}-\left(q_{1}+q_{2 H}\right)-c\right) \\
& +(1-\theta) q_{1}\left(a_{L}-\left(q_{1}+q_{2 L}\right)-c\right) \\
& =q_{1} \theta\left(\left(a_{H}-a_{L}\right)-\left(q_{2 H}-q_{2 L}\right)\right) \\
& +q_{1}\left(a_{L}-\left(q_{1}+q_{2 L}\right)-c\right) .
\end{aligned}
$$

While

$$
\begin{aligned}
& u_{2 H}\left(q_{1}, q_{2 H}\right)=q_{2 H}\left(a_{H}-\left(q_{1}+q_{2 H}\right)-c\right) \\
& u_{2 L}\left(q_{1}, q_{2 L}\right)=q_{2 L}\left(a_{L}-\left(q_{1}+q_{2 L}\right)-c\right) .
\end{aligned}
$$

The quantities $q_{2 H}^{*}, q_{2 L}^{*} \quad$ solve $\underset{0 \leq q_{2 H}<\infty}{\operatorname{Max}} u_{2 H}\left(q_{1}^{*}, q_{2 H}\right), \underset{0 \leq q_{2 L}<\infty}{\operatorname{Max}} u_{2 L}\left(q_{1}^{*}, q_{2 L}\right)$ respectively. The first-order conditions for firm 2's optimization problem are obtained by the derivative of the payoff functions above:

$$
\begin{aligned}
& \frac{d u_{2 H}\left(q_{1}^{*}, q_{2 H}\right)}{d q_{2 H}}=a_{H}-\left(q_{1}^{*}+q_{2 H}\right)-c+q_{2 H}(-1) \\
& =a_{H}-\left(2 q_{2 H}+q_{1}^{*}\right)-c,
\end{aligned}
$$


Southeast Europe Journal of Soft Computing Volume 1. Number 1 March 2012

$$
\begin{aligned}
& \frac{d u_{2 L}\left(q_{1}^{*}, q_{2 L}\right)}{d q_{2 L}}=a_{L}-\left(q_{1}^{*}+q_{2 L}\right)-c+q_{2 L}(-1) \\
& =a_{L}-\left(2 q_{2 L}+q_{1}^{*}\right)-c .
\end{aligned}
$$

Equating these derivatives to zero one gets:

$q_{2 H}^{*}=\frac{1}{2}\left(a_{H}-q_{1}^{*}-c\right), q_{2 L}^{*}=\frac{1}{2}\left(a_{L}-q_{1}^{*}-c\right)$.

On the other hand $q_{1}^{*}$ solves

$$
\begin{aligned}
& \operatorname{Max}_{0 \leq q_{1}<\infty} u_{1}\left(q_{1}, q_{2 H}^{*}, q_{2 L}^{*}\right)= \\
& \operatorname{Max}_{0 \leq q_{1}<\infty}\left\{\begin{array}{l}
\theta q_{1}\left(a_{H}-\left(q_{1}+q_{2 H}^{*}\right)-c\right) \\
+(1-\theta) q_{1}\left(a_{L}-\left(q_{1}+q_{2 L}^{*}\right)-c\right)
\end{array}\right\} \\
& =\operatorname{Max}_{0 \leq q_{1}<\infty}\left\{\begin{array}{l}
q_{1} \theta\left(\left(a_{H}-a_{L}\right)-\left(q_{2 H}^{*}-q_{2 L}^{*}\right)\right. \\
+q_{i}\left(a_{L}-\left(q_{1}+q_{2 L}^{*}\right)-c\right)
\end{array}\right\} .
\end{aligned}
$$

The first-order condition for firm 1's optimization problem is:

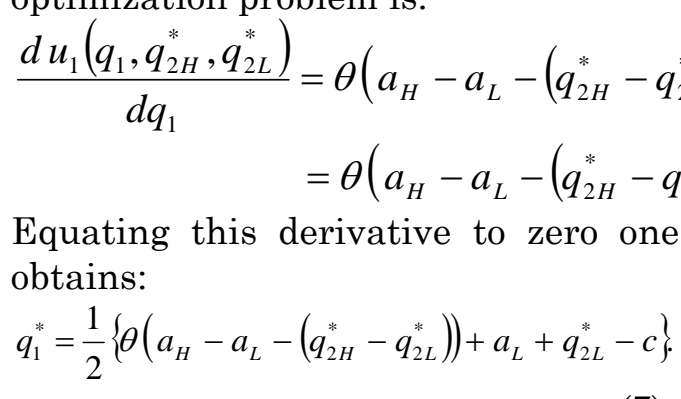

Simultaneous solutions of linear algebraic equations (6) and (7) in $\left(q_{1}^{*}, q_{2 H}^{*}, q_{2 L}^{*}\right)$ leads to

$$
\begin{aligned}
& q_{1}^{*}=\frac{1}{2}\left\{\theta\left(a_{H}-a_{L}-\frac{1}{2}\left(a_{H}-a_{L}\right)\right)\right. \\
& \left.+a_{L}-\frac{1}{2}\left(a_{L}-q_{1}^{*}-c\right)-c\right\} \\
& \frac{3}{4} q_{1}^{*}=\frac{1}{4}\left\{\theta\left(a_{H}-a_{L}\right)+\left(a_{L}-c\right)\right\} \\
& q_{1}^{*}=\frac{1}{3}\left\{\theta a_{H}+(1-\theta) a_{L}-c\right\} ;
\end{aligned}
$$

And

$$
\begin{aligned}
q_{2 H}^{*} & =\frac{1}{6}\left(3 a_{H}-\left(\theta a_{H}+(1-\theta) a_{L}-c\right)-3 c\right), \\
& =\frac{1}{6}\left((3-\theta) a_{H}-(1-\theta) a_{L}-2 c\right), \\
q_{2 L}^{*} & =\frac{1}{6}\left(3 a_{L}-\left(\theta a_{H}+(1-\theta) a_{L}-c\right)-3 c\right), \\
& =\frac{1}{6}\left((3-(1-\theta)) a_{L}-\theta a_{H}-2 c\right) .
\end{aligned}
$$

Hence $\left(q_{1}^{*}, q_{2 H}^{*}, q_{2 L}^{*}\right)$ is the Nash equilibrium of this game with

$$
\begin{aligned}
& q_{1}^{*}=\frac{1}{3}\left\{\theta a_{H}+(1-\theta) a_{L}-c\right\}, \\
& q_{2 H}^{*}=\frac{1}{6}\left((3-\theta) a_{H}-(1-\theta) a_{L}-2 c\right), \\
& q_{2 L}^{*}=\frac{1}{6}\left((3-(1-\theta)) a_{L}-\theta a_{H}-2 c\right) .
\end{aligned}
$$

To have nonnegative $\left(q_{1}^{*}, q_{2 H}^{*}, q_{2 L}^{*}\right)$,

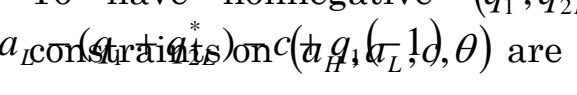

\section{REFERENCES}

Cournot, A. 1838. Recherches sur les

Prindpes Mathe'matiques de la Theorie des Richesses. English edition: Researches into the Mathematical Principles of the Theory of Wealth. Edited by N, Bacon. New-York: Macmillan, 1897.

Edgeworth, F.Y. 1881, Mathematical Psychics, London: Kegan Paul.

Gibbons, R. 1992. Game theory For Applied Economists, Princeton University Press.

Nash, J. 1950. Equilibrium Points in n-Person Games. Proceedings of the National Academy of Sciences 36:4849. 